\title{
Squamous cell carcinoma of the penis and marital status: survival study and risk assessment on mortality
}

\author{
Tomoyuki Kawada
}

Received: 30 January 2013/Accepted: 16 March 2013/Published online: 26 March 2013

(C) Springer Science+Business Media Dordrecht 2013

I read with interest the effect of marital status on mortality in patients with squamous cell carcinoma of the penis (SCCP) [1]. Sexual behavior-related factors such as human papillomavirus infection, having sexually transmitted diseases, and the number of sexual partner have been known as the risk of SCCP. The authors mentioned the lack of information on marital status in the last paragraph of "Discussion", and marital status is an important factor to receive health support from his family members.

I have a query on their study outcome. The authors clarified that married status is a protective factor on mortality of SCCP. This means that unmarried status becomes a risk factor. On this point, they categorized unmarried status into one group by compiling single, widowed, divorced, or separated men. I previously reported that divorced subjects had a risk of poor self-rated health (SRH), but single or bereaved subjects did not show significant relationship with poor SRH [2]. As poor SRH was a significant risk factor of mortality by overviewing the past reports [3], stratification of unmarried status into several groups should be considered [4]. As the effect of unmarried status on mortality was also affected by activity limitation or poor activity of daily living [5], the additional analysis to check the interaction of variables should be considered.

There were enough number of events in their study, and the statistical power is satisfactory. This means that more stratified variables can be handled for their analysis. For example, they mentioned that more specific socioeconomic status (SES) could be used for their analysis. SES is defined by several factors including occupational class, academic carrier, or income, but caution should also be paid for the ethnic difference in SES [6].

In anyway, their report presents important information on the effect of marital status on mortality of SCCP, and I strongly recommend them to disentangle different strata of the "unmarried" group for specifying their analysis.

\section{References}

1. Thuret R, Sun M, Budaus L, Abdollah F, Liberman D, Shariat SF, Iborra F, Guiter J, Patard JJ, Perrotte P et al (2013) A populationbased analysis of the effect of marital status on overall and cancerspecific mortality in patients with squamous cell carcinoma of the penis. Cancer Causes Control 24(1):71-79

2. Kawada T, Suzuki S (2011) Marital status and self-rated health in rural inhabitants in Japan: a cross-sectional study. J Divorce Remarriage 52(1):48-54

3. Kawada T (2003) Self-rated health and life prognosis. Arch Med Res 34(4):343-347

4. Artazcoz L, Cortes I, Borrell C, Escriba-Aguir V, Cascant L (2011) Social inequalities in the association between partner/marital status and health among workers in Spain. Soc Sci Med 72(4):600-607

5. Zheng H, Thomas PA (2013) Marital status, self-rated health, and mortality: overestimation of health or diminishing protection of marriage? J Health Soc Behav. doi:10.1177/0022146512470564

6. Kawada T (2012) Occupational class as the indicator of socioeconomic position. Occup Environ Med 69(8):606-607

T. Kawada $(\bowtie)$

Department of Hygiene and Public Health, Nippon Medical

School, 1-1-5 Sendagi, Bunkyo-Ku, Tokyo 113-8602, Japan

e-mail: kawada@nms.ac.jp 